\title{
Behavioural pattern in changes to diets and food availability during broodstock conditioning of captive clam Ruditapes decussates
}

\author{
Yassine Ouagajjou ${ }^{{ }^{*}}$, Adil Aghzar ${ }^{2}$, Meriem Ahensal ${ }^{3}$, Nadia Berday ${ }^{3}$, and Mohamed \\ Idhalla $^{1}$ \\ ${ }^{1}$ National Institute of Fisheries Research, Departement of Aquaculture, Casablanca, Morocco \\ ${ }^{2}$ Polydisciplinary Faculty of Larache FPL, Abdelmalek Essâadi University, Tetouan, Morocco \\ ${ }^{3}$ Institute of Agromony and Veterinary Sciences Hassan II, Rabat, Morocco
}

\begin{abstract}
In terms of the nutritional needs, the choice of the appropriate phytoplankton strain is the main criterion during bivalves breeding improvement in captivity. Seven nutritional diets based on tree microalgae species (Chaetoceros calcitrans, Tetraselmis suecica and Pavlova lutheri), and seven feeding rations $(0 \%, 1 \%, 2 \%, 3 \%, 4 \%, 5 \%$ and $6 \%)$ were used to assess the nutritional pattern of Ruditapes decussatus during conditioning practices. All regimes have shown the highest ingestion rate at low food availability $(1 \%$ to $3 \%)$ with a leaning to diets based on C. Calcitrans followed by $T$. suecica and $P$. lutheri respectively.A significant influence of diets quality on absorption efficiency of phytoplankton was observed for both monospecific and bispecific diets $\left(\mathrm{F}=21.78, \mathrm{p}=3.210^{-7} * * *\right.$ and $\mathrm{F}=$ $250.09, \mathrm{p}=2.210^{-16} * * *$ respectively). Whereas, low influence of food availability on absorption efficiency among all used rations has been revealed by clams reared under mono, bi and trispecific diets respectively $\left(\mathrm{F}=11,19, \mathrm{p}=1.910^{-7} * * * ; \mathrm{F}=16,63, \mathrm{p}=1.0310^{-9} * * *\right.$ and $\mathrm{F}=2.78$, $\left.\mathrm{p}=0.0534^{\mathrm{ns}}\right)$. Consequently, this study could be handled as a standard protocol for conditioning process in furtherance of yield maximizing and cost minimizing during spat production of bivalves in hatcheries.
\end{abstract}

\section{Introduction}

The clam Ruditapes decussatus is a common species in the estuarine and lagoon areas of most of the Mediterranean basin [1,2]. It is globally widespread from the British Isles coastlines to the Mediterranean Sea until the Red Sea and along the Atlantic coasts of Africa from Morocco until Senegal [3-6]. Several studies related to many aspects were carried out on clams in terms of its biology and ecology $[3,7,8,9,10]$, its ecotoxicology [11-14], its breeding in captivity [15-19] and to physiological energetic and biochemical parameters [20-22]. In Morocco, it is distributed all across the marine ecosystems (bays, lagoons and estuaries) from Alboran Sea to the south Atlantic coasts [23, 24].With its

\footnotetext{
*Corresponding author: ouagajiou@inrh.ma
} 
excellent organoleptic qualities and economic importance, $R$. decussatus represents a great commercial value as one of the most frequently harvested bivalves in the Mediterranean [25]. Consequently, this clam has been heavily fished in all across its habitats along Moroccan coastlines [23, 25]. Accordingly, a management strategy has been imposed recently to preserve this resource and to regulate its fishery activities. [26] proposed a clam conservation strategy based on morphological variations which were thereafter applied on local populations in order to define their morphometric patterns [27]. In addition, the establishment of management strategy depends on spat production process in captivity inside hatcheries in order to ensure the sustainability production of shellfish aquaculture.

Broodstock conditioning for spawning is a crucial step which allows extending spat production season regardless the short period of natural maturity in wild beds. During breeding process, the major aim of broodstock conditioning is to achieve highest gametes release and maximum fecundity of clams whilst improving gametes quality and viability [28-30]. This achievement depends essentially on feeding practices during conditioning where microalgae are the only trophic source during broodstock conditioning and their production is one of the most important practices in mollusks hatchery [31]. The nutritional quality and cost benefit assessment of the different species of microalgae used in hatcheries for many species of bivalves have been studied during the last decade [32-36]. Therefore, broodstock maturation appears to be more controlled by food quantity and quality rather than other factors such as temperature, salinity and photoperiod [19].

Through the past years, many studies were performed in terms of using bio-deposition method to assess feeding and absorption rates in bivalves [20, 37] in order to optimize feeding regimes and rations during broodstock conditioning. From eco-physiological standpoint, the influence of quality and availability of food on maturation and biomass production is equated to the particular effect of each physiological aspect such as ingestion, digestion and absorption capacities [38]. The aim of the present research was to evaluate the effect of multispecific microalgae diets and suitable food ration on physiological patterns like consumption, ingestion and absorption during locale clam (Ruditapes decussatus) broodstock.

\section{Materials and Methods}

\subsection{Clam sampling and broodstock conditioning}

All the experiments were conducted during June 2019, at the Station of Shellfish Research, located in the marine area of Amsa (Alboran Sea, Tetouan, Morocco). The biological material consisted of 430 adult specimens of the local clam (weight $=13.78 \pm 3.03 \mathrm{~g}$; length $=40.33 \pm 3.27 \mathrm{~mm}$ ) collected from natural populations from Kabila $\left(35^{\circ} 43^{\prime} 04^{\prime}\right.$ ' $\mathrm{N} / 5^{\circ} 20^{\prime} 06^{\prime \prime} \mathrm{W}, \mathrm{M}^{\prime}$ diq, Morocco), then rinsed and placed in $20 \mathrm{~L}$ tanks and held in a closed water system. An average of 10 individuals per tank was used for each experiment under natural conditions of temperature $\left(19{ }^{\circ} \mathrm{C}\right)$, salinity (36 PSU), $\mathrm{pH}(8-8,3)$ and dissolved oxygen $(6.4 \pm 0.5 \mathrm{mg} / \mathrm{L})$. Forty adults were randomly chosen in order to calculate their mean dry weight according to [21]. Before carrying out feeding tests, all adults were held to fast during $48 \mathrm{~h}$ in order to get totally rid of their faeces. 


\subsection{Feeding process}

Three species of live microalgae were used (Chaetoceros calcitrans, Pavlova lutheri and Tetraselmis suecica). Three types of regimes (Diet-A, Diet-B and Diet-C) were held during this experiment with different composition. Three monospecific regimes (Diet-A1: 100\% P. lutheri; Diet-A2: $100 \%$ C. calcitrans and Diet-A3: 100\% T. suecica), three bispecific regimes (Diet-B1: 65\% P. lutheri $+35 \%$ C. calcitrans; Diet-B2: 80\% P. lutheri $+20 \%$ T. suecica and Diet-B3: 75\% T. suecica $+25 \%$ C. calcitrans) and one Trispecific regimes (Diet-C: $50 \%$ P. lutheri $+25 \%$ T. suecica $+25 \%$ C. calcitrans). Furthermore, for each diet we established seven feeding rations in triplicate as described by [28] $(1 \%, 2 \%, 3 \%, 4 \%$, $5 \%$ and $6 \%$ of clam dry weight) in addition to control diet ( $0 \%$ : only natural seawater). For all experiments (except the control), only $0.2 \mu \mathrm{m}$ filtered seawater was used in a closed rearing system.

\subsection{Physiological patterns}

The consumption of microalgae in each experiment was handled by counting the number of cells each thirty minutes during three hours from different level of rearing tanks (bottom, middle and surface). By the end of each experiment, early at the evening, the decanted feces in breeding tanks are recovered and quantified according to [21]. In order not to overestimate the feces weight measurements, the pseudo-faeces occurrence was taken into account according to [21] before collecting of the fecal matter.

- Consumption was estimated according to [21]: $C=(N 1-N 2) \times P s / P i$;

(1)

Where N1: Initial number of microalgae; N2: Final number of microalgae; Ps: Dry weight of microalgae $(\mathrm{g}) ; P i$ : Dry weight of clam flesh $(\mathrm{g}) ; P 0$ : weight of the pseudo-faeces $(\mathrm{g})$; $P F$ : weight of fecal matter $(\mathrm{g})$.

\subsection{Statistical analysis}

In order to estimate the effect of each treatment (diet and ration) on each calculated parameter, a two-way analysis of variance (ANOVA) was performed at a 95\% level of confidence $(\alpha=0.05)$. When ANOVAs were significant, the post hoc Tukey multiple comparison test was used to determine which treatments differed. All statistical tests were analyzed using Rcmdr interface [40] implemented in R package version 3.1.2 [41].

\section{Results}

\subsection{Ingestion rate and consumption}

For monospecific diets, the results reported in Figure 1A show a large difference in terms of ingestion rate (IR) between the food rations used during this study. For instance, clams reared under Diet-A2 (C. calcitrans) have revealed the highest IR (approximately $100 \%$ ) 
for all feeding rations, followed by clams reared under Diet-A3 (T. suecica) especially at the first three feeding rations. Diet-A1 (P. lutheri) has shown the highest IR only for $1 \%$ of feeding rations.
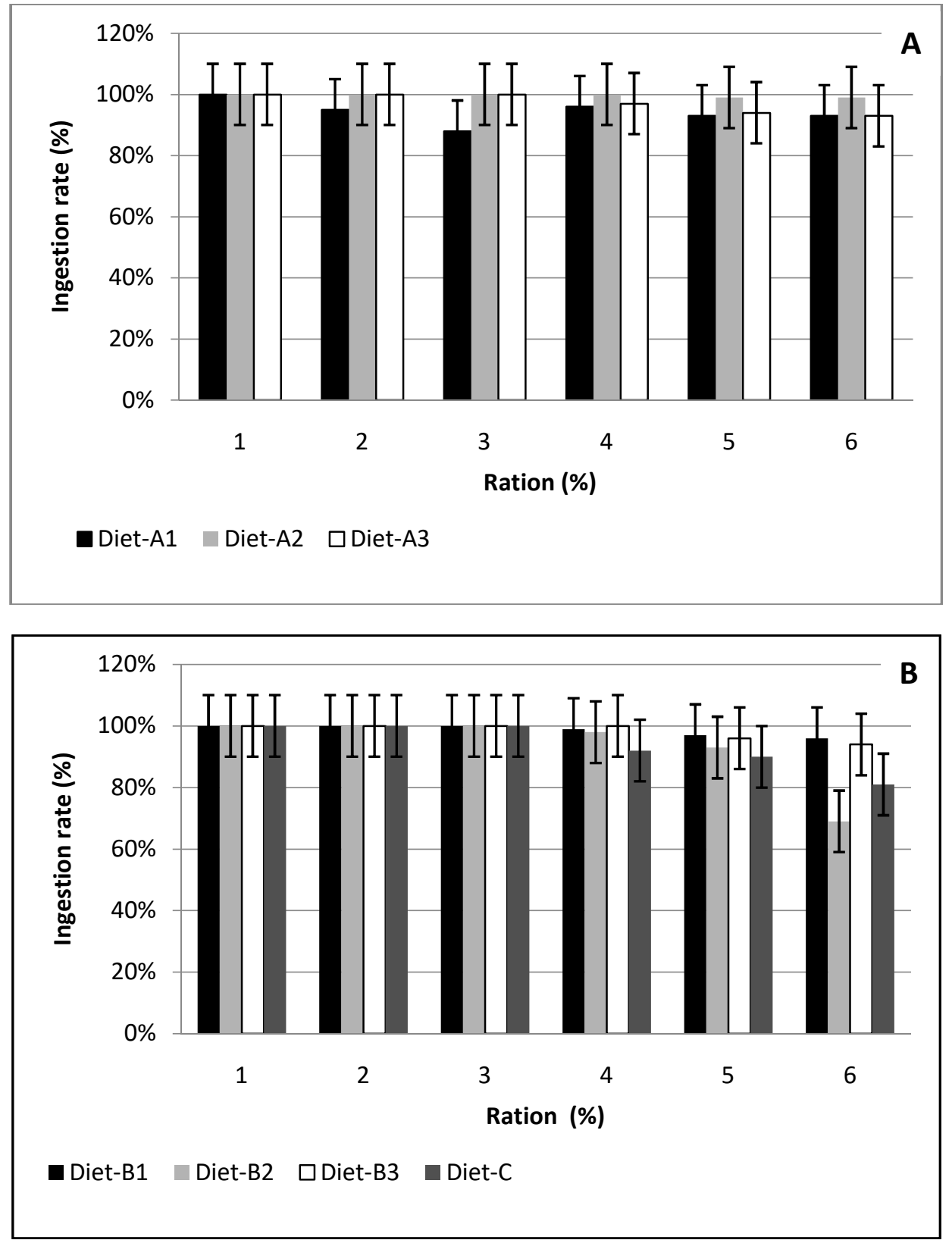

Fig.1.Ingestion rate (\%) of clam $R$. decussatus exposed to different microalgae diets ((A): monospecific diets Diet-A1 (100\% P. lutheri), Diet-A2 (100\% C. calcitrans) and Diet-A3 (100\% T. suecica); (B): Multispecific diets (Bispecific diets: Diet-B1 (65\% P. lutheri $+35 \%$ C. calcitrans), Diet-B2 $(80 \%$ P. lutheri $+20 \%$ T. suecica $)$, Diet-B3 $(75 \%$ T. suecica $+25 \%$ C. calcitrans $)$ and Trispecific diet: Diet-C $(50 \%$ P. lutheri $+25 \%$ T. suecica $+25 \%$ C. calcitrans $))$ and food ration (\%) during broodstock conditioning, (Vertical bars indicate SD) 
As regards multi-specific diets, the IR varies remarkably from one diet to another and shows an outstanding difference regarding microalgae composition of each diet. All regimes have shown the highest IR at low food availability $(1 \%$ to $3 \%)$. Whereas, at high food availability, clams showed less capacity of IR (Fig. 1B). Taking into account the specific ingestion within each diet, we clearly observed that clams reared under bispecific (Diet-B) have revealed the highest IR toward $C$. calcitrans followed by $T$. suecica and $P$. lutheri, respectively.

For trispecific (Diet-C), the best IR (100\%) was also registered at low food availability ( $1 \%$ to $3 \%$, Fig. 1B). Regarding the specific IR, we observed that C. calcitrans is thoroughly ingested for all feeding rations, followed by $P$. lutherie which has been fully ingested during almost the feeding rations, while less IR toward T. suecica was remarkably observed when multispecific diet is used. However, we note that clams reared under natural seawater ( $0 \%$ ration) have shown $100 \%$ of IR during this study. Moreover, the highest effective consumption of microalgae was recorded at $6 \%$ of feeding ration across all studied regimes (data not shown).

As regards the amount (post-ingestion) of consumed food (generally after pseudo-faeces lifting),we observed the significant effect of both diet and ration on food ingestion for clams during conditioning process (Table 1). For instance, for monospecific diets, the food ingestion is highly influenced by the quality of microalgae $(F=126.7, P<0.001)$ rather than food availability $(F=44.6, P<0.001)$. Whereas, for bispecific diets, the ingestion is extremely influenced by both ration and diet respectively $(F=579.7, P<0.001$ and $F=$ 454.2, $P<0.001)$. Moreover, the ingestion of clams fed with trispecific diet have been also highly influenced by the ration $(F=557.8, P<0.001)$. In view of the influence of feeding patterns (diet and ration) on clam ingestion, the highest effect was observed across all rations $(F=298.06, P<0.001)$ followed by the effect of diets $(F=190.53, P<0.001)$ and the interaction of diet and ration $(F=16.44, P<0.001)$.

Table 1. Two-way ANOVA of the effect of different regimes and feeding rations on the ingestion. Diet-A: Monospecific diets, Diet-B: Bispecific diets, Diet-C: Trispecific diet, Sum Sq: Sum of square,

Df: degrees of freedom, F: value of Fisher test, Pr: probability of error, ***: highly significant at 1 $\%$ )

\begin{tabular}{|l|l|c|c|c|c|}
\cline { 3 - 6 } \multicolumn{2}{c|}{} & Sum Sq & Df & F value & $\operatorname{Pr}(>\mathbf{F})$ \\
\hline \multirow{3}{*}{ Diet-A } & Diet & 0.316 & 2 & 126.75 & $2.210^{-16 * * *}$ \\
& Ration & 0.334 & 6 & 44.61 & $2.210^{-16 * * *}$ \\
& Diet-Ration & 0.246 & 12 & 16.44 & $3.5410^{-12 * * *}$ \\
\hline \multirow{3}{*}{ Diets-B } & Diet & 0.152 & 2 & 454.29 & $2.210^{-16 * * *}$ \\
& Ration & 0.585 & 6 & 579.78 & $2.210^{-16 * * *}$ \\
& Diet-Ration & 0.049 & 12 & 24.45 & $3.89910^{-15 * * *}$ \\
\hline \multirow{3}{*}{ Diet-C } & Ration & 0.255 & 6 & 557.87 & $7.77210^{-16 * * *}$ \\
\hline \multirow{3}{*}{ Total } & Across diets & 0.706 & 6 & 190.53 & $2.210^{-16 * * *}$ \\
& Across rations & 1.105 & 6 & 298.06 & $2.210^{-16} * * *$ \\
& Diets-Rations & 0.365 & 36 & 16.44 & $2.210^{-16} * * *$ \\
\hline
\end{tabular}

\subsection{Absorption efficiency and Absorption rate}

For monospecific diets, in terms of the evolution of the absorption efficiency (Fig. 2A), clams rise their AE while increasing food availability until ration 3\% (54\%, and $83 \%$ for Diet-A2 and Diet-A3, respectively) and until ration 5\% (80\% for Diet-A1). In the 
meanwhile, within monospecific diets, clams fed on Diet-A3 have shown high performance in terms of $\mathrm{AE}$ comparing to other diets during the first feeding ration.
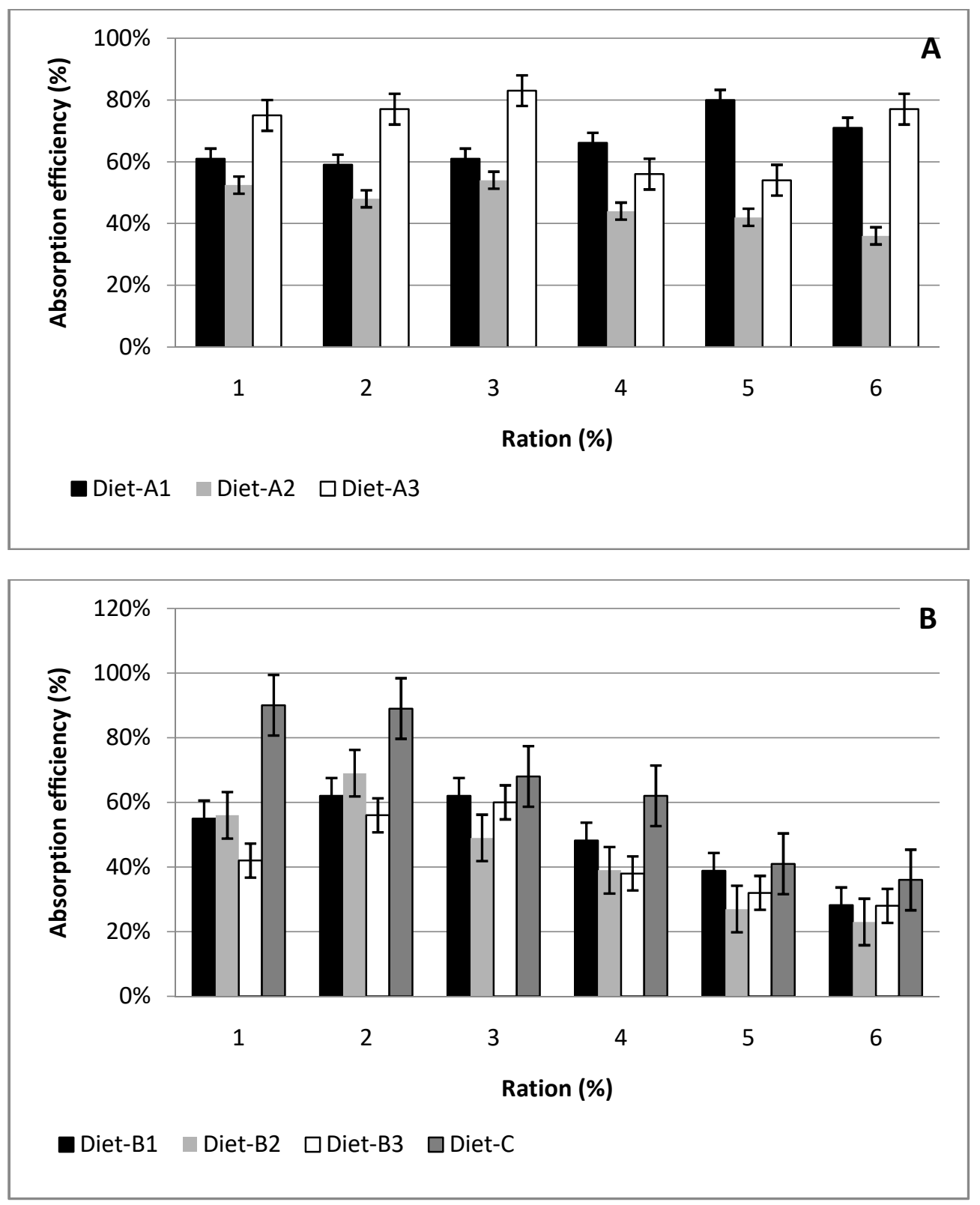

Figure 2. Absorption efficiency (\%) of clam R. decussatus exposed to different experimental microalgae diets ((A): monospecific diets Diet-A1 (100\% P. lutheri), Diet-A2 (100\% C. calcitrans) and Diet-A3 (100\% T. suecica); (B): Multispecific diets (Bispecific diets: Diet-B1 (65\% P. lutheri + $35 \%$ C. calcitrans), Diet-B2 (80\% P. lutheri $+20 \%$ T. suecica) $)$ Diet-B3 $(75 \%$ T. suecica $+25 \%$ C. calcitrans) and Trispecific diet: Diet-C (50\% P. lutheri $+25 \%$ T. suecica $+25 \%$ C. calcitrans $))$ and food ration (\%) during broodstock conditioning, (Vertical bars indicate SD)

For multispecific diets (Fig. 2B), we observed that clams rise their AE depending on food availability until a certain limit where this efficiency decrease progressively even 
though food ration increases. The highest value of AE (90\% and $89 \%)$ was registered for clams fed on trispecific diets (Diet-C) especially at low food availability (1\% and 2\% respectively) then decreases remarkably starting from the ration $4 \%$.

According to two-way ANOVA analysis (Table 2), the absorption rate is much more influenced by the regime quality for clams fed with a combination of two microalgae species (bispecific diets) $(F=250.1, \mathrm{df}=2, P<0.001)$ than clams fed with monospecific diets $(F=21.7, \mathrm{df}=2, P<0.001)$. As regards feeding ration, the absorption was also significantly influenced for both clams fed with bispecific and monospecific diets respectively $(F=16.63, P<0.001$ and $F=11.19, P<0.001)$. Whereas, no significant difference has been observed in terms of the influence of the availability of food on the absorption rate for clams fed with trispecific diet $(F=2.7, P=0.0534)$. In view of the effect of all diets and rations on the absorption rate of clams, the highest influence was observed across all diets $(F=44.10, P<0.001)$ followed by the effect of rations $(F=17.19, P<$ $0.001)$ and the interaction of diet and ration $(F=5.45, P<0.001)$.

Table 2. Two-way ANOVA of the effect of different regimes and feeding rations on the absorption rate. Diet-A: Monospecific diets, Diet-B: Bispecific diets, Diet-C: Trispecific diet, Sum Sq: Sum of square, Df: degrees of freedom, F: value of Fisher test, Pr: probability of error, ${ }^{* *}$ : significant at $1 \%$; $* * *$ : highly significant at $1 \%$, ${ }^{\text {ns: }}$ : not significant)

\begin{tabular}{|l|l|c|c|c|c|}
\cline { 3 - 6 } \multicolumn{2}{l|}{} & Sum Sq & Df & F value & Pr(>F) \\
\hline \multirow{3}{*}{ Diet-A } & Diet & 0.006 & 2 & 21.78 & $3.210^{-7} * * *$ \\
& Ration & 0.010 & 6 & 11.19 & $1.910^{-7} * * *$ \\
& Diet-Ration & 0.006 & 12 & 3.59 & $0.001^{* *}$ \\
\hline \multirow{3}{*}{ Diets-B } & Diet & 0.010 & 2 & 250.09 & $<2.210^{-16} * * *$ \\
& Ration & 0.002 & 6 & 16.63 & $<1.0310^{-9} * * *$ \\
& Diet-Ration & 0.003 & 12 & 13.65 & $7.0910^{-11 * * *}$ \\
\hline \multirow{3}{*}{ Total-C } & Ration & $3.0210^{-5}$ & 6 & 2.78 & $0.0534^{\mathrm{ns}}$ \\
& Across diets & 0.019 & 6 & 44.10 & $<2.210^{-16} * * *$ \\
& Across rations & 0.007 & 6 & 17.19 & $1.7310^{-13 * * *}$ \\
& Diets-Rations & 0.014 & 36 & 5.45 & $1.2210^{-11} * * *$ \\
\hline
\end{tabular}

\section{Discussion}

Different responses in terms of nutritional behavior of $R$. Decussates broodstock have been observed as regards food availability and diets quality during this study. Our results have shown that feeding based on monospecific diet Diet-A2 (C. calcitrans) have the best ingestion rate recorded across this experience, flowed by Diet-A3 ( $T$. suecica) at only the first three rations (moderated food availability). The highest observed IR of these two strains can be explained by their ease ingestion by bivalves [42, 22]. Beyond the moderated ration, the IR decreases systematically for all diets even though consumption increases (data not shown), which can be explained by the saturation of food-transport mechanism [43]. Inversely, other studies have found that the ingestion capacity is saturated and a functional response occurs decreasing the filtration rates (which is not congruent with our results) in order to keep the IR at maximum level [32, 44, 45, 46, 47, 48, 49, 21]. In parallel, sometimes ingestion can also be regulated by increasing production of pseudo- 
faeces and remaining the IR constant $[45,50]$. In our case, neither regulation nor constant ingestion rate has been recorded. Instead, our results are consistent with [43] where the IR increases when food availability is moderated and decreases at saturated feeding rations [43]. According to [51], maximum feeding rates in Venerupis pullastra depends on the natural habitat of the species where particle concentrations are normally low which is congruent with our study at starved situation (100\% of IR at $0 \%$ ration: natural sea water).

As regards multispecific diets, the best ingestion rate was generated with bispecific Diet-B3 ( $C$. calcitrans and $T$. suecica) during moderated food availability including a specific leaning toward $C$. calcitrans across all rations. However, such result can explain the early maturity of the $R$. Decussates broodstock during conditioning process using $C$. calcitrans alone or mixed with T. Suecica [52].Taking into consideration the IR and absorption are the main physiological processes governing spat growth, [53] reports that the combination of $C$. calcitrans and $P$. lutherie also generates significant filtration and good growth during Crassostrea gigas larvae rearing. The maximum ingestion recorded for C. calcitrans even under multi-specific diets shows a certain type of specific preference towards this microalgae that might be referred to its high carbohydrate content [52].

Generally, bivalves digest and absorb the ingested microalgae with different efficiencies [54]. At very low food availability, the ingested food is directly digested in the digestive gland with high efficiency and the remaining unassimilated matter is rejected as glandular faeces [46]. Whereas, at high concentrations of particles (cells of microalgae), the absorption efficiency was very low. This could surely due to the formation of pseudofaeces which generates difficulties in separating normal microalgae cell from pseudo-faeces ones [43]. However, as the seston concentration increases, the excess of phytoplankton entering the stomach bypasses the digestive gland and is rejected undigested as intestinal faeces [55]. This inverse correlation between the ingestion rate and absorption efficiency has been previously described in other species of mollusks [20, 21, 47, 56, 57] and even in fishes [58].

Nevertheless, the extremely low or negative absorption efficiencies might be due to unsuitable, indigestible food, abnormal physiological state of the bivalve or to experimental errors in the measurement of the faeces [20]. Moreover, several difficulties in separating faeces from pseudo-faeces could result in an underestimating of the absorption efficiency calculated using the Conover method. On the other hand, the production of pseudo-faeces means an overestimation of the ingestion rate [43].

Differences in degree of regulation of ingestion and absorption were also achieved herein in terms of food quality (dietary composition). This observation has been previously described by several authors $[45,59]$ indicating a preferential ingestion of the algal component in the mixture diet. At a certain pseudo-faeces threshold, the absorption efficiency increases with increasing food quality. This interactive effect between food quality and availability has been also reported for Mytilus edulis [60] and $M$. galloprovincialis [61]. This mechanism has been explained by [59], by the fact that at high particle concentrations, pseudo-faecal production becomes a significant component of total bio-deposition as quality of food decreases and pre-ingestive selection results in an enrichment of ingested ration; consequently, "true" absorption efficiency tends to increase with increasing filtration in diets of low organic content. So, when feeding on diets of high organic content, bivalves do not achieve a significant enrichment of food upon ingestion and, for rising particle concentration, a reduction in absorption efficiency would take place in spite of partial regulation of ingestion rate. Resulting effects of food availability on absorption are thus minimal. To summarize, feeding behavior of clams (as cockles) 
exposed to varying concentrations of particles of low food value which suggest that, in turbid environments, bivalves maximize net energy gain by maintaining high selection efficiencies and high rates of pseudo-faeces production. In conclusion, the degree in which pseudo-faeces formation contributes to regulate ingestion varies according to food availability and quality.

\section{Conclusion}

In conclusion, many uncertainties over the mechanism of seston capture or the role of physiological process, still exist concerning fundamental traits of feeding behavior in suspension feeding bivalves. Therefore, from a shellfish standpoint, a moderated availability of food (generally 3-4\% DW daily), is the target food ration to maximize biomass increase and minimize feeding loss. In addition, this relatively moderated food level was also the optimum ration, since it corresponded to the maximum efficiency of conversion of food into biomass. In the industrial scale, bivalve seed production should attempt to combine both economic and physiological criteria in order to guaranty high growth rate.

\section{References}

1. A. Parache, La pêche Maritime, 1254, 496-507(1982)

2. P. E. Lubet, Haliotis, 14:49-68 (1984)

3. J. M. Poutiers, Bivalves (Acephales, Lamellibranches, pélécypodes). In: Fischer, W., M. L. Bauchot et M. Schneider (ed.), Fiches FAO 'identification des espèces pour les besoins de la pêche. (Révision 1). Volume I (Végétaux et Invertébrés) FAO, pp: 371 512 (1987)

4. M. Roméo, M. M. Gnassia-Barelli, Camp. Biochem. Physiol.,111 C (3),457-463(1995)

5. M. Puigcerver, Aquaculture Research,27,399-404 (1996)

6. A. Gharbi,K. Said, A.V. Wormhoudt,J. Shellfish Res34, 791-801 (2015)

7. F. Garcia, Oceanologica Acta. 16, 199-203 (1993)

8. J. Aníbal, E. Esteves, C. Rocha, J. Shellfish Res. 30(1), 17-23 (2011)

9. R. Moreira, P. Balseiro, A. Romero, S. Dios, D. Posada, B. Novoa, A. Figueras, Dev Comp Immunol 36,140-149 (2012)

10. A. Derbali, A. Hadj Taieb, W. Kammoun, J. Gouirah, A. Wannes-Ghorbel, N. Zamouri-Langar, M. Ghorbel, O. Jarboui, J. Mar. Biol. Assoc. U. K., 96(1), 177-184 (2016)

11. S. Chora, M. Starita-Geribaldi, J. M. Guigonis, M. Samson, M. Roméo, M.J. Bebianno., Aquat. Toxicol., 94, 300-308 (2009)

12. C. Velez, E. Figueira, A. Soares, R. Freitas, Estuar. Coast. Shelf Sci., 155, 114-125. (2015a)

13. C. Velez, P. Galvão, R. Longo, O. Malm, A.M.V.M Soares, E. Figueira, R. Freitas, Environ. Sci. Pollut. Res., 1-15 (2015b)

14. H. Chalghmi, I. Zrafi, P. I. Gourves, J. P. Bourdineauda, D. Saidane-Mosbahib, Environ. Sci.: Processes Impacts, 18, 895-907 (2016)

15. M. Delgad, A.Perez-Camacho, Bol. Inst. Esp. Oceanogr. 18 (1-4): 293-300 (2002) (In Spanish)

16. M. Delgado, A.Perez-Camacho, Sci. Mar, 71, 471-484 (2007) 
17. E. M. Gosling, Oxford, OX2OEL, Fishing News Books: 443pp. (2003)

18. J. Ojea, A. J. Pazos, D. Martínez, S. Novoa, P. García-Martínez, J. L. Sánchez, M. Abad, J Shellfish Res 27(5):1093-1100 (2008)

19. D. Matias, S. Joaquim, A.M. Matias, A. Leitão, Invertebr Reprod Dev 60(1):49-58 (2016)

20. R. Beiras, A. Perez-Camacho, M. Albentosa, Aquaculture 116(4):353-365 (1993)

21. R. Beiras, A. Pérez-Camacho, Mar. Biol. 120, 427-435 (1994)

22. M. Albentosa, A. Pérez-Camacho, U. Labarta, M.J. Fernández-Reiriz, Aquaculture 148(1):11-23 (1996c)

23. M. S. Shafee, M. Daoudi, Aquac. Res., 22, 203-216 (1991)

24. A. Kamara, N. Rharbi, A. Berraho, M. Ramdani, Mar. Life. 15 (1-2), $43-50$ (2005)

25. A. Kamara, N. Rharbi, M. Ramdani, A. Berraho, Bull. Soc. Zool. France, 133, 189198 (2008)(In French).

26. N. Caill-Milly, N. Bru, M. Barranger, L. Gallon, F. D'amico, J. Shellfish Res, 33, 355372 (2014)

27. Z. Amane, L. Tazi, M. Idhalla, M. Chlaida, AACL Bioflux12 (5), 1623-1634 (2019)

28. S. D. Utting, P. F. Millican, Aquaculture. 155, 45-54 (1997)

29. F. da Costa, A. Cerviño-Otero, Ó. Iglesias, et al. Aquacult Int 28, 1675-1708 (2020)

30. Y. Ouagajjou, T. El Aloua, M. El Moussaoui, E. M. Ait Chattou, A. Aghzar, Y. Saoud, AACL Bioflux 13(6):3664-3673 (2020)

31. P. Coutteau, P. Sorgeloos, J Shellfish Res 11, 467-476 (1992)

32. P. R. Walne, J. Mar. Biol Assoc. U.K. 52, 345-374 (1972)

33. C. E. Epifanio, Aquaculture, 18, 1 - 12 (1979)

34. CT. Enright, G. F. Newkirk, J.S. Craigie, J. D. Castell, J. Exp. Mar. Biol. Ecol., 96, 113 (1986)

35. 1. Laing, P. F. Millican, Aquaculture, 54, 245-262 (1986)

36. A. Aghzar, M. Minambres, P. Alvarez, P. Presa, Thalassas, 29,9-16 (2013)

37. J. I. P. Iglesias, M .B. Urrutia, E. Navarro, I. Ibarrola,J. Exp. Mar. Biol. Ecol. 219, 7186 (1998)

38. I. Martínez-Pita, C. Sánchez-Lazo, F.J. García, Aquacult. Nutr., 22, 202-216 (2016)

39. R. J. Conover, Limnol Oceanogr2,338-354 (1966)

40. J. Fox, M.Bouchet-Valat, Rcmdr. R Commander. R package version 2, 3-1 (2016).

41. R Development Core Team. R: A language and environment for statistical computing. R Foundation for Statistical Computing, Vienna, Austria, ISBN 3-900051-07-0, UR (2008)

42. M. RBrown,. Nutritional value of microalgae for aquaculture. In: Cruz-Suárez LE, Ricque-Marie D, Tapia-Salazar M, Gaxiola-Cortés MG, Simoes N (eds) Advances en Nutrición Acuícola VI. Memorias del VI Simposium Internacional de Nutrición Acuícola, 3-6 Septiembre 2002. Cancún, Quintana Roo, México (2002)

43. M. Albentosa, A. Pérez-Camacho, R. Beiras,AquacNutr2(4):213- 220 (1996b)

44. E. H. Schulte, Mar Biol30, 331-341 (1975)

45. R. L. Foster-Smith. J. exp. Mar Biol. Ecol. 17, 1-22 (1975)

46. J. Widdows, R. Fieth, C.M. Worrall, 50,195 -207 (1979) 
47. J. M. Navarro, J. E. Winter. Mar Biol, 67, 255-266 (1982)

48. D. Gerdes, Aquaculture 31, 195- 219 (1983)

49. V.M. Bricelj, R.E. Malouf,Mar Biol84, 155 - 165 (1984)

50. E. Navarro, J. I. P. Iglesias, M.M. Ortega. J exp mar Biol Ecol, 156, 69-87 (1992)

51. K. R. Tenore, W. M. Dunstan, J. Exp. Mar. Biol.(1973)

52. A. S. Abbas, E. El-Wazzan, A. R. Khafage, A. F. M. El-Sayed, F. A. A. Razek. Aquacult Int 26, 1297-1309 (2018)

53. E. Ponis, G. Parisi, G. Chini Zittelli, F. Lavista, R. Robert, MR. Tredici. Aquaculture, 282, 97-103 (2008)

54. B. L. Bayne, R.C. Newell,. Physiological energetics of marine molluscs. In: The Mollusca. Vol 4. Physiology, Part I (Saleuddin, A.S.M. \& Wilbur, K.M., eds), pp. 407515. Academic Press, New York(1983)

55. P. B. Van Wee1,1, 245-252(1961)

56. P. Calow, Oecologia, 20, 33-49 (1975a)

57. J. Widdows, B.L. Bayne, D. R. Livingstone, R. I. E. Newell, P.Donkin, Comp. Biochem. Physiol. (1978a)

58. J.M. Elliott, J. Anim. Ecol.(1976)

59. J. I. P. Iglesias et al., J. Exp. Mar. Biol. Ecol. (1992)

60. B. L. Bayne, A.J.S. Hawkins, E.Navarro,111,1-22 (1987)

61. E. Navarro, J. I. P. Iglesias, A. Perez Camacho, U. Labarta, R. Beiras, Aquaculture, 94, 197-212 (1991) 